Contract No. and Disclaimer:

This manuscript has been authored by Savannah River Nuclear Solutions, LLC under Contract No. DE-AC09-08SR22470 with the U.S. Department of Energy. The United States Government retains and the publisher, by accepting this article for publication, acknowledges that the United States Government retains a non-exclusive, paid-up, irrevocable, worldwide license to publish or reproduce the published form of this work, or allow others to do so, for United States Government purposes. 


\title{
Development and Selection of Ionic Liquid Electrolytes for Hydroxide Conducting Polybenzimidazole Membranes in Alkaline Fuel Cells
}

\author{
Elise B. Fox* ${ }^{1}$, Héctor R. Colón-Mercado ${ }^{1}$, Yuanxin Chen ${ }^{2}$, \\ W.S. Winston $\mathbf{H o}^{2}$
}

1. Savannah River National Laboratory, Aiken, SC 29808, (803)507-8560, elise.fox@srnl.doe.gov

2. Ohio State University, Columbus, $\mathrm{OH}$

Alkaline fuel cell (AFC) operation is currently limited to specialty applications such as low temperatures and pure $\mathrm{H}_{2} / \mathrm{O}_{2}$ due to the corrosive nature of the electrolyte and formation of carbonates. AFCs are the cheapest and potentially most efficient (approaching $70 \%$ ) fuel cells. The fact that non-Pt catalysts can be used, makes them an ideal low cost alternative for power production. The anode and cathode are separated by and solid electrolyte or alkaline porous media saturated with KOH. However, $\mathrm{CO}_{2}$ from the atmosphere or fuel feed severely poisons the electrolyte by forming insoluble carbonates. The corrosivity of $\mathrm{KOH}$ (electrolyte) limits operating temperatures to no more than $80^{\circ} \mathrm{C}$. This chapter examines the development of ionic liquids electrolytes that are less corrosive, have higher operating temperatures, do not chemically bond to $\mathrm{CO}_{2}$, and enable alternative fuels. Work is detailed on the IL selection and characterization as well as casting methods within the polybenzimidazole based solid membrane. This approach is novel as it targets the root of the problem (the electrolyte) unlike other current work in alkaline fuel cells which focus on making the fuel cell components more durable.

RESERVE THIS SPACE 


\section{Introduction}

Alkaline Fuel Cells (AFCs) differ from typical Proton Exchange Membrane Fuel Cells (PEMFC) in that the reactions occur in a basic environment. Because the electrolyte is basic, oxygen at the cathode is reduced to hydroxide ions that are transported through the cell to the anode where they combine with hydrogen to produce water. The schematic of an AFC is found in Figure 1. Because of the basic nature, slow reactions, such as those at the cathode can occur at faster rates, eliminating kinetic limitations that typically affect PEMFCs. This fact proves advantageous enabling the use of alternative electrocatalysts to $\mathrm{Pt}$ at the cathode electrode. Typically AFCs operate at low temperatures due to the corrosive nature of the electrolyte, which could be dissolved $\mathrm{KOH}$ or solid polymer hydroxide ions conductors. The use of new solid conductors has created renewed interest in AFCs. They enable the use of air, instead of pure oxygen, without the detrimental effects typically seen from the binding of $\mathrm{CO}_{2}$ present in air with the hydroxide salts forming insoluble carbonates. However, solid proton conductors still have major limitations in temperatures, stabilities, conductivities, and manufacturability. In this work we began studying a new and un-explored alternative route to solving all of the issues plaguing AFCs, which consists on the use of stable easy to manufacture polymers impregnated with ionic liquids.

AFCs are the highest performing fuel cell systems even though ongoing issues with the electrolyte and electrode degradation has hindered their advancement. For optimal operation, it is necessary to maintain high hydroxyl conductivity and maintain stability in a high $\mathrm{pH}$ environment ${ }^{1}$. The formation of insoluable carbonates $\left(\mathrm{CO}_{3}{ }^{2-}\right)$ and/or bicarbonates $\left(\mathrm{HCO}_{3}{ }^{-}\right)$, which are formed by the reaction of $\mathrm{OH}^{-}$(from aqueous $\mathrm{NaOH}$ or $\mathrm{KOH}$ ) ion with $\mathrm{CO}_{2}$ (contamination from the oxidation stream) is one of the largest hinderances of widescale implementation. The formation of these insoluble carbonates/bicarbonates creates the largest problem in the electrodes because they cause blockages within the electrolyte-filled pores that destroy the active layers. 


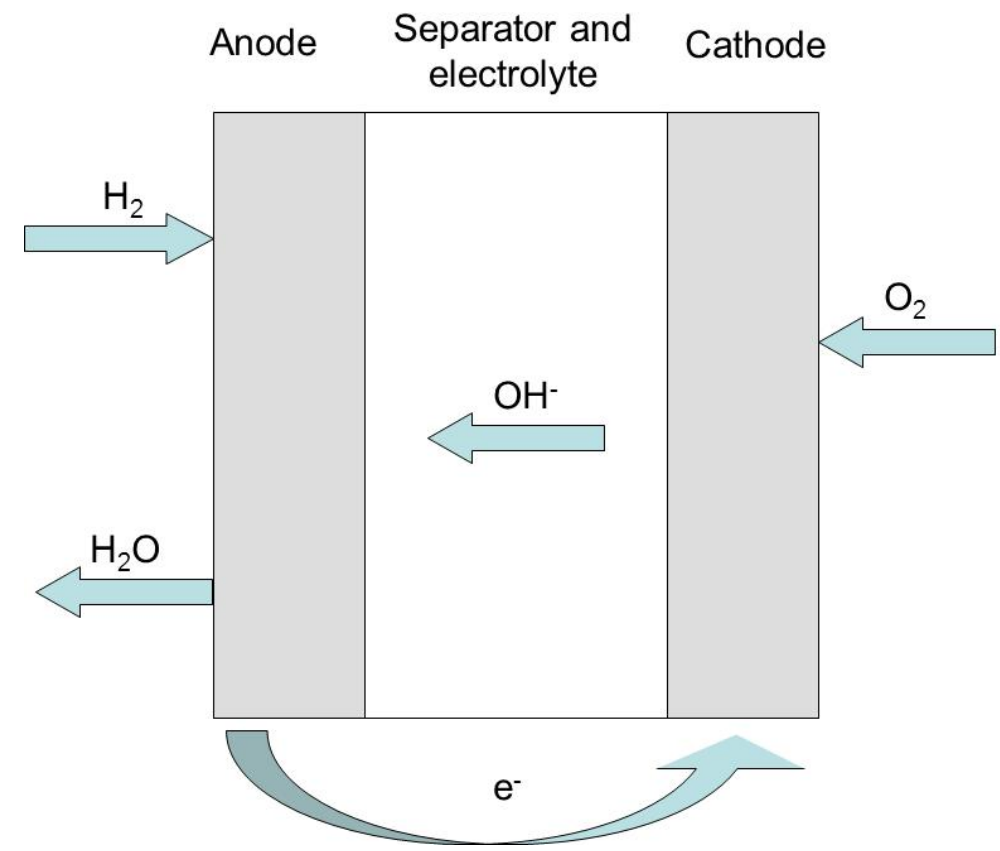

Figure 1. Schematic of an AFC during operation.

One of the benefits of IL electrolytes is that they do not form these insoluble carbonates in large quantities ${ }^{2-3}$. While the choice of anion can largely influence the solubility and adsorption ability of the IL for $\mathrm{CO}_{2}$, the chain length of the anion did not play as large of a role ${ }^{4}$. In addition to $\mathrm{CO}_{2}$ solubility, the large electrochemical window of ILs makes them favorable as fuel cell electrolytes 5 .

Anion exchange membranes based on quaternized polymers have been used for $\mathrm{AFCs}^{6-7}$, however the polymer has proved unstable at high temperatures due to the nucleophilic displacement through the Hofmann elimination reaction ${ }^{8}$. To overcome these limitations, polybenzimidazole (PBI) membranes have been used as separator. PBI membranes are well known for their excellent chemical stability at high temperatures, low permeability and high ionic conductivity when doped with phosphoric acid or sulfuric acid ${ }^{9}$. While acid doped PBI membranes have been used in PAFC for many years, their performance is limited by the strong anion adsorption on the Pt catalysts. Hydroxide doped PBI has been studied and shown to possess both endurance in alkali medium and high temperatures ${ }^{6,9}$. It has been shown to have high ionic conductivity and comparable performance to PEMFC. However, the use of hydroxide salts constrains the oxidant gas feed to only low carbon dioxide oxidant feeds, as the 
presence of $\mathrm{CO}_{2}$ will react with the hydroxide salts and form carbonate precipitates ${ }^{10}$.

Protic-ILs have been proposed and studied as proton conduction enhancers for PEMFC either by doping the membranes with $\mathrm{IL}^{11-14}$ or by polymerizing the ionic liquid into membranes ${ }^{15}$. The purpose of the use of IL for PEMFC has mostly focused on the extension of PEMFC to operate at high temperatures higher than $120^{\circ} \mathrm{C}$ where the humidity levels are low and the effect of impurities in the fuel streams are minimal. Nakamoto et al. showed that with the right combination of IL acid and bases the high temperature electrochemical performance for the hydrogen oxidation reaction (HOR) and the oxygen reduction reaction (ORR) at the Pt electrode can be facilitated and even surpassed the performance of a phosphoric acid or sulfuric acid solutions ${ }^{12}$. The performance improvement has been attributed to the higher proton activities and lower negative adsorption of ions on to the electrode surface. While significant progress has been made during the last few years, improvements on ionic conductivity and high performance under load must continue.

\section{Ionic Liquid Characterization}

\section{Experimental}

All ionic liquids described here-in were purchased off- the shelf from Ionic Liquid Technologies, with the exception of 1-butyl-3-methylimidazolium bis(perfluoroethylsulonyl)imide $\quad\left[\mathrm{C}_{4} \mathrm{mim}\right][\mathrm{BETI}] \quad$ and 1-butyl-3methylimidazolium hydroxide $\left[\mathrm{C}_{4} \mathrm{mim}\right][\mathrm{OH}]$ which are described below.

\section{Ionic Liquid Synthesis}

\section{$\left[\mathrm{C}_{4}\right.$ mim][BETI]}

A 1:1 molar ratio of 1-butyl-3-metylidizolium chloride (Aldrich) and $\mathrm{Li}$ bis(perfluoroethylsulfonyl)imide $(3 \mathrm{M})$ were mixed together and covered in $300 \mathrm{~mL}$ of deionized water. The mixture was allowed to stir for 30 minutes after all salts were dissolved. The solution was allowed to settle into two phases. The organic phase was washed with DI water and allowed to settle for thirty minutes. This process was repeated three times. The washed organic phase was then bubbled with dry $\mathrm{N}_{2}$ for 24 hours to help dry the resulting ionic liquid.

$\left[\mathrm{C}_{4} \underline{\operatorname{mim}}\right][\mathrm{OH}]$ 
1-butyl-3-methylimidazolium hydroxide was made from a procedure derived from $\operatorname{Refs}^{16-17} \cdot 0.2 \mathrm{~mol}$ of $\left[\mathrm{C}_{4} \mathrm{mim}\right][\mathrm{Cl}]$ was added to $150 \mathrm{~mL}$ of tetrahydrofuran and stirred for 30 minutes until dissolved. An excess of $\mathrm{NaOH}(0.25 \mathrm{~mol})$ was added and stirred for 22 hours. Gravity filtration was used to remove $\mathrm{NaCl}$ solids that were formed. THF was removed from the filtered solution via rotoevaporator to obtain a bright yellow liquid. The rotoevaporator conditions were changed to remove any residual water and left for 90 minutes. The remaining ionic liquid was washed three times with $50 \mathrm{~mL}$ of diethylether and rotoevaporated at $80^{\circ} \mathrm{C}$. The remain IL was now a dark viscous solution. Composition was confirmed by FT-IR, see Figure 2, and a bulk conductivity of $102 \mu \mathrm{S} / \mathrm{cm}$ was measured for the product. FT-IR peaks are similar in location to those reported by Ranu and Banerjee ${ }^{17}$.

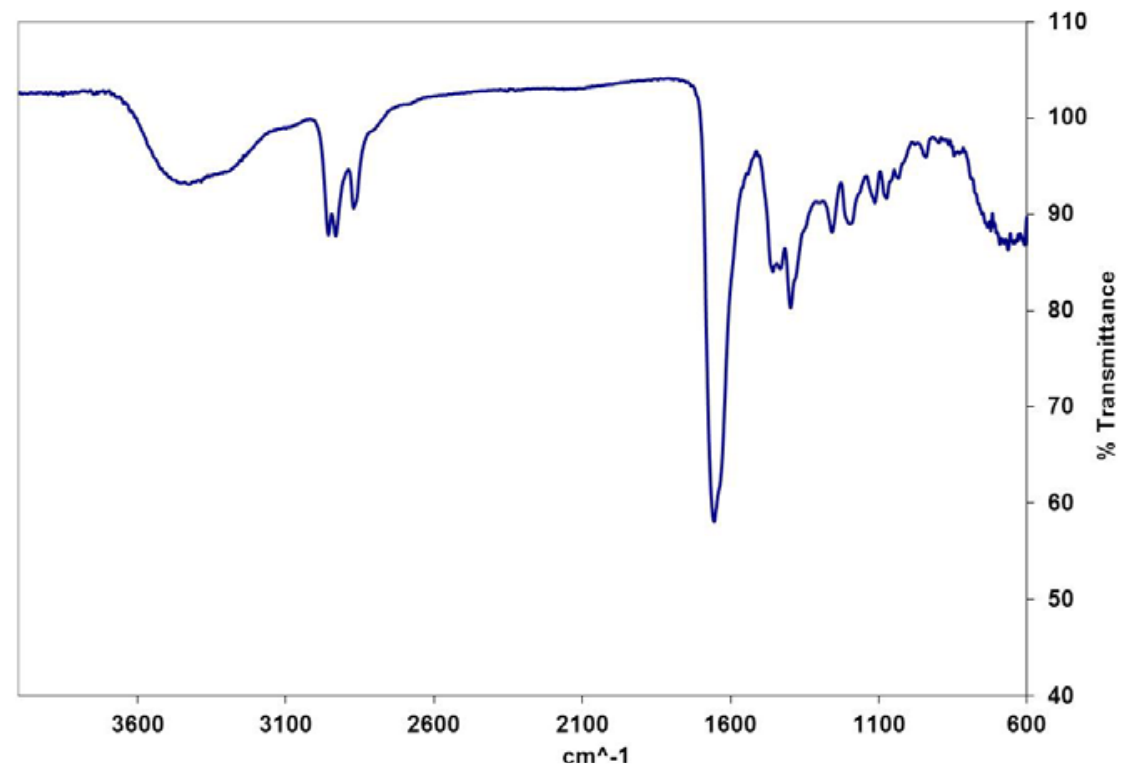

Figure 2. FT-IR spectra of $\left[\mathrm{C}_{4} \mathrm{mim}\right][\mathrm{OH}]$.

\section{Bulk IL Conductivity}

Bulk conductivity was measured on a Fisher Scientific Accumet Excek XL60 Meter using a two prong K-type ion conductivity probe with $1 \mathrm{~cm}^{2}$ active area at $25^{\circ} \mathrm{C}$. The probe was calibrated with conductivity standards at 10,000 $\mu \mathrm{S} / \mathrm{cm}, 1,000 \mu \mathrm{S} / \mathrm{cm}$ and $100 \mu \mathrm{S} / \mathrm{cm}$ before measurement of the ILs. Figure 3 
shows the effect of cation on conductivity. All ionic liquids have the common anion bis(trifluorpmethylsulfonyl)imide. The imidazolium cations have the highest conductivity. The high ion conductivity of the imidazole has been attributed to the fact that it has both proton donor and acceptor groups within the molecule ${ }^{18}$. This is reduced when a methyl group is substituted for the C-2 proton. The lowest conductivity is seen with the 1,1,1,-trimetylammonium 1butyric acid cation.

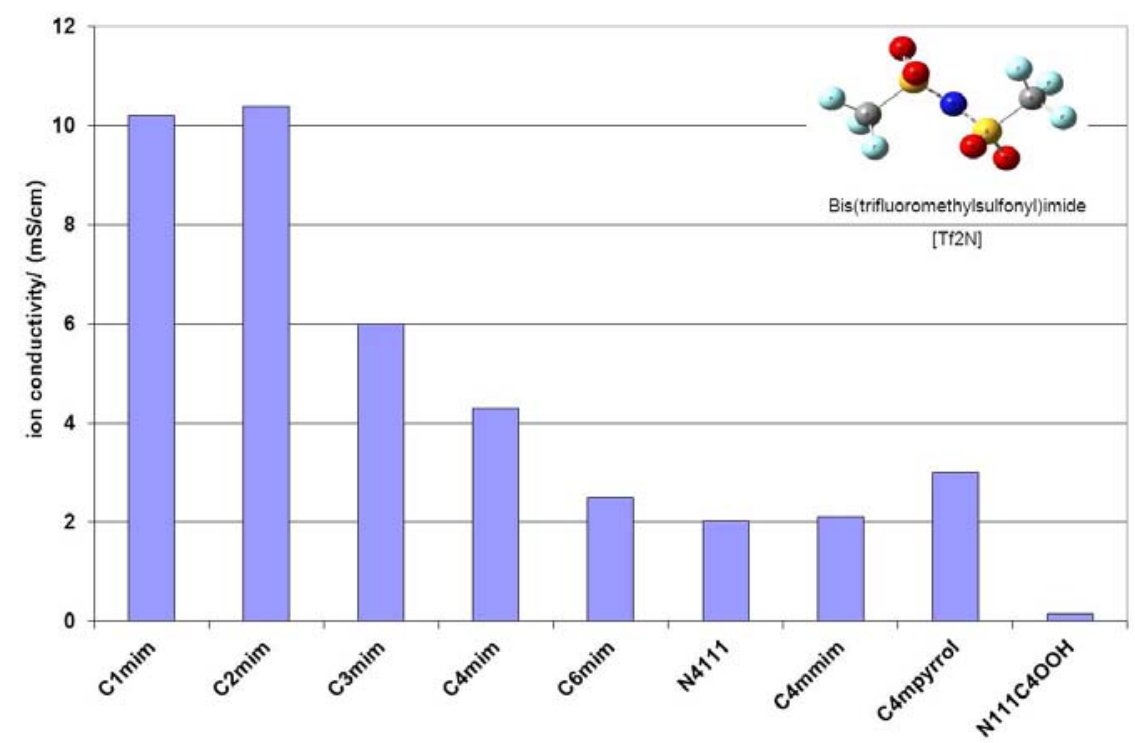

Figure 3. Bulk conductivity of ionic liquids with the common anion $\left[\mathrm{Tf}_{2} \mathrm{~N}\right]$.

The effect on conductivity by changing the anion is seen in Figure 4. All ILs examined have the common cation 1-butyl-1-methyl imidazolium. The $\left[\mathrm{Tf}_{2} \mathrm{~N}\right]$ had the highest conductivity, followed by $\left[\mathrm{BF}_{4}\right]$ and [triflate]. [ $\left[\mathrm{BF}_{4}\right]$ would be a poor candidate for this application due to ability to strongly hydrogen bonf to water. ${ }^{19-20}$ [triflate] has been investigated for use in fuel cells and has seen some success. ${ }^{21-22}$ 


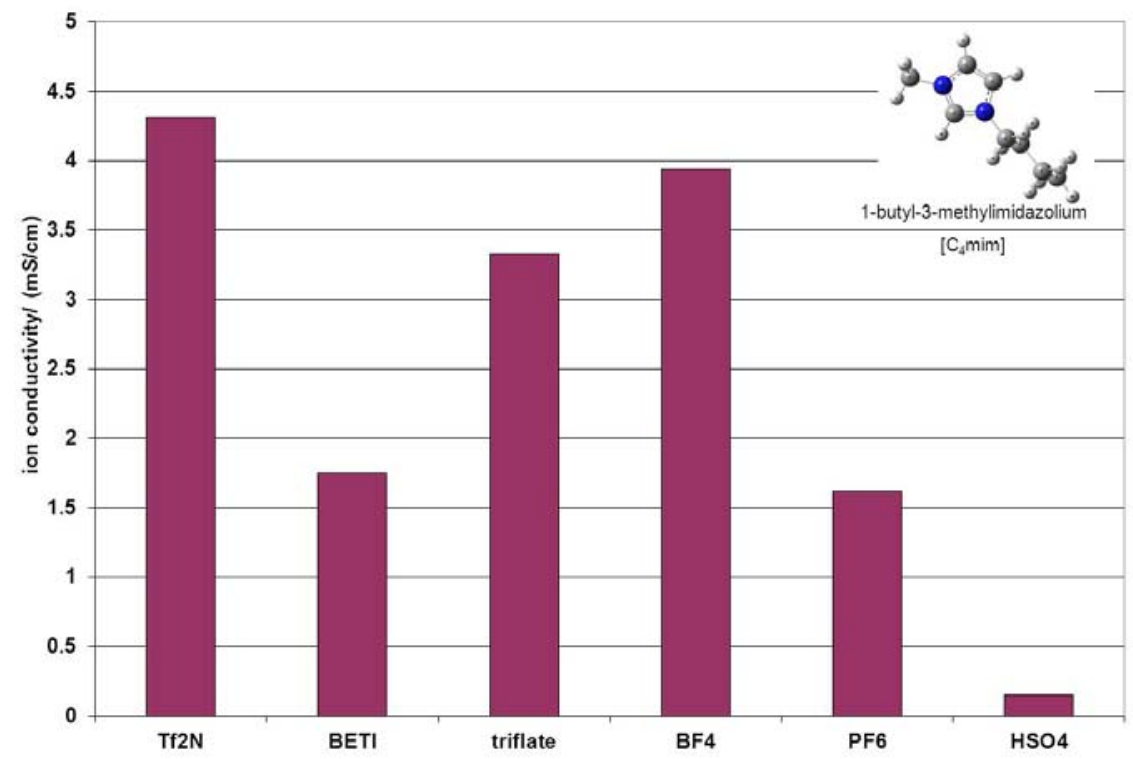

Figure 4. Bulk conductivity of ionic liquids with the common cation $\left[\mathrm{C}_{4} \mathrm{mim}\right]$.

\section{Thermogravimetric Analysis}

An important component of extending the operating range of AFCs relies not only on conductivity of the electrolyte, but also thermal stability. If an electrolyte can operate at higher temperature ranges, the operating window for the cell can be extended and total efficiencies can be increased.

Thermogravimetic analysis (TGA) was utilized to determine the thermal stability of all ILs described here-in. All TGA experiments were conducted under a $\mathrm{N}_{2}$ atmosphere using a Netzsch $209 \mathrm{~F} 1$ thermal gravimetric analyzer with single use $\mathrm{Al}$ crucibles at a ramp rate of $10^{\circ} \mathrm{C} /$ minute. The thermal analysis software (Proteus V5.2.0) calculates the thermal onset temperature based on the intersection of the baseline with the tangent, at the inflection point, of the decomposition rate.

Figure 5 shows the how the side chain length on the imidazole effects thermal stability. All defined temperatures are also reported in Table 1. As the length of the chain increases, the thermal stability of the IL decreases. A thrity degree decrease in stabily can be found between a $\mathrm{C}_{6}$ substituted imidazole and 
a $\mathrm{C}_{1}$ substituted imidazole. This indicates that as the side chain lengthens, it is more easily cleaved from the cation during heating. By keeping a common anion and changing the cation from $\left[\mathrm{N}_{111} \mathrm{C}_{4} \mathrm{OOH}\right]$ to $\left[\mathrm{C}_{1}\right.$ mim], there is a 94 degree incrase in thermal stability.

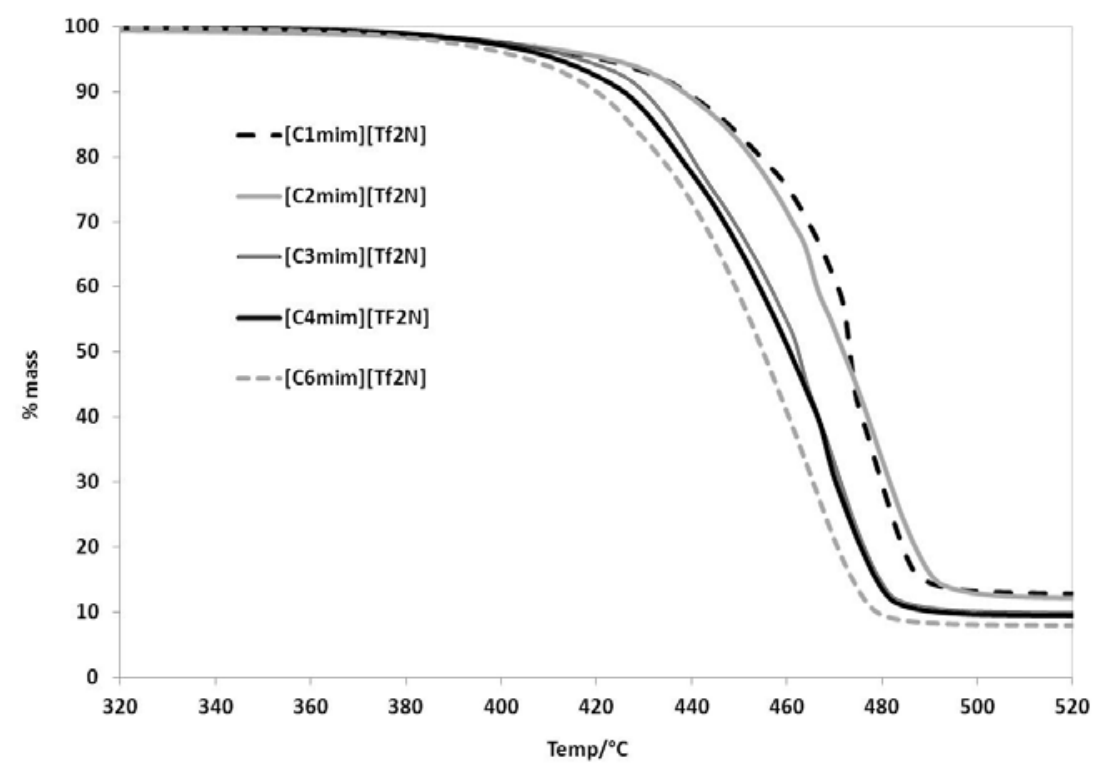

Figure 5. Effect of side chain length on [1-N-3-methylimidazolium $]\left[\mathrm{Tf}_{2} \mathrm{~N}\right]$ on thermal stability of IL.

Alternatively, changes in the anion do not necessarily effect the thermal stability as dramatically as changing the cation does. As seen in Figure 6, there is only a thirty degree difference between common IL cations. However, when the cation is in hydroxide form, we see a significant decrease in the thermal stability, a drop to $203^{\circ} \mathrm{C}$. This is an important indicator of complex molecules that will be present within an AFC membrane operating with IL electrolytes, so it will limit the operating window at $200^{\circ} \mathrm{C}$ for the system. 
Table 1. Summary of decomposition temperatures and bulk conductivity of all ILs screened in this work.

\begin{tabular}{|c|c|c|}
\hline Ionic Liquid & $\begin{array}{l}\text { Decomposition } \\
\text { Temperature } /{ }^{\circ} \mathrm{C}\end{array}$ & $\begin{array}{c}\text { Conductivity/ } \\
\mathrm{mS} / \mathrm{cm}\end{array}$ \\
\hline$[\mathrm{mim}]\left[\mathrm{Tf}_{2} \mathrm{~N}\right]$ & 402.0 & Solid at room temp. \\
\hline$\left[\mathrm{C}_{1} \mathrm{mim}\right]\left[\mathrm{Tf}_{2} \mathrm{~N}\right]$ & 472.5 & 10.21 \\
\hline$\left[\mathrm{C}_{2} \mathrm{mim}\right]\left[\mathrm{Tf}_{2} \mathrm{~N}\right]$ & 463.5 & 10.40 \\
\hline$\left[\mathrm{C}_{3} \mathrm{mim}\right]\left[\mathrm{Tf}_{2} \mathrm{~N}\right]$ & 460.2 & 6.014 \\
\hline$\left[\mathrm{C}_{4} \mathrm{mim}\right]\left[\mathrm{Tf}_{2} \mathrm{~N}\right]$ & $443.2^{23}$ & 4.313 \\
\hline$\left[\mathrm{C}_{6} \mathrm{mim}\right]\left[\mathrm{Tf}_{2} \mathrm{~N}\right]$ & 429.2 & 2.504 \\
\hline$\left[\mathrm{C}_{4} \mathrm{mmim}_{[}\left[\mathrm{Tf}_{2} \mathrm{~N}\right]\right.$ & $459.0^{23}$ & 2.124 \\
\hline$\left[\mathrm{N}_{4111}\right]\left[\mathrm{Tf}_{2} \mathrm{~N}\right]$ & $435.0^{23}$ & 2.022 \\
\hline$\left[\mathrm{C}_{4} \mathrm{mpyrr}_{[}\left[\mathrm{Tf}_{2} \mathrm{~N}\right]\right.$ & $435.7^{23}$ & 3.009 \\
\hline$\left[\mathrm{C}_{4} \mathrm{~N}_{11} \mathrm{pyr}\right]\left[\mathrm{Tf}_{2} \mathrm{~N}\right]$ & $465.3^{23}$ & 2.500 \\
\hline$\left[\mathrm{N}_{111} \mathrm{C}_{4} \mathrm{OOH}\right]\left[\mathrm{Tf}_{2} \mathrm{~N}\right]$ & $379.1^{23}$ & 0.149 \\
\hline$\left[\mathrm{C}_{4} \mathrm{mim}\right]\left[\mathrm{PF}_{6}\right]$ & 425.1 & 1.616 \\
\hline$\left[\mathrm{C}_{4} \mathrm{mim}\right]\left[\mathrm{BF}_{4}\right]$ & 389.8 & 3.936 \\
\hline$\left[\mathrm{C}_{4} \mathrm{mim}\right][\mathrm{BETI}]$ & $417.9^{23}$ & 1.748 \\
\hline$\left[\mathrm{C}_{4} \mathrm{mim}\right][$ triflate] & 394.1 & 3.332 \\
\hline$\left[\mathrm{C}_{4} \mathrm{mim}\right][\mathrm{OH}]$ & 203.2 & 0.102 \\
\hline$\left[\mathrm{C}_{4} \mathrm{mim}\right]\left[\mathrm{HSO}_{4}\right]$ & 388.5 & 0.149 \\
\hline Benzalkonium chloride & 187.7 & Solid at room temp. \\
\hline
\end{tabular}




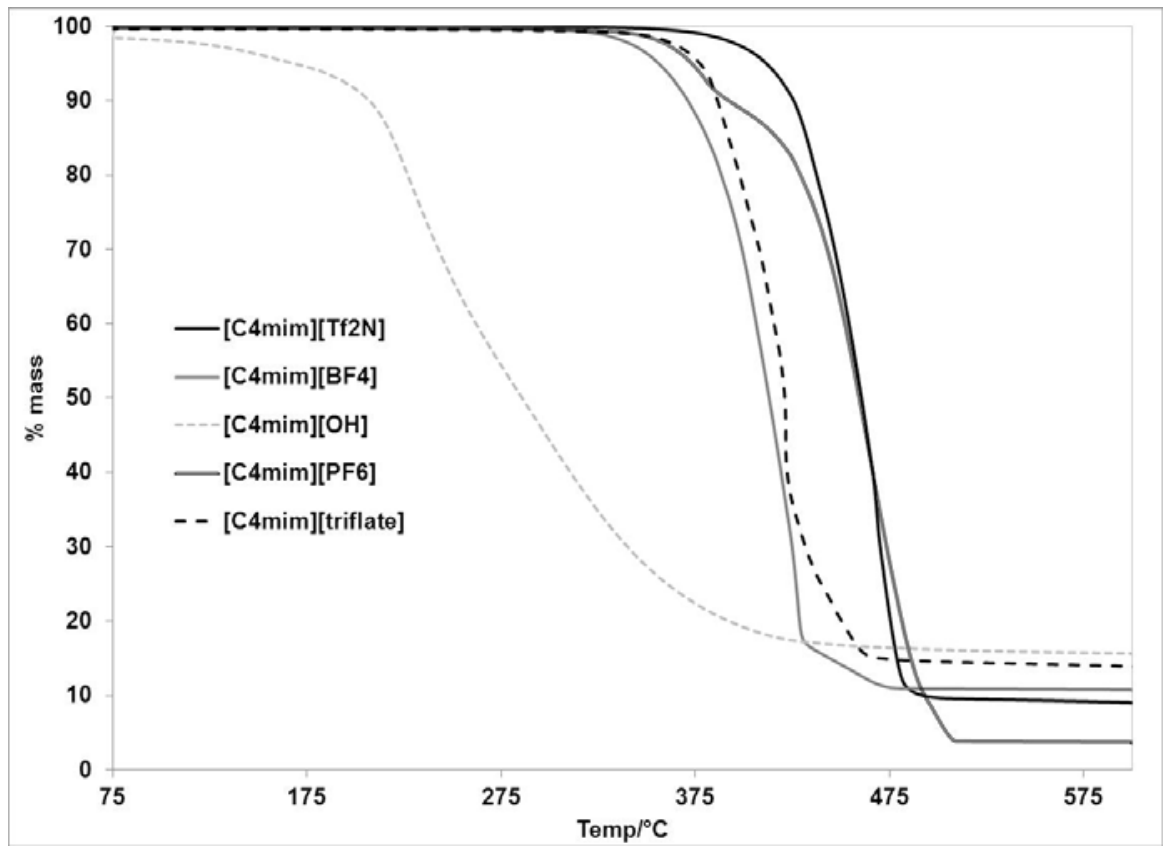

Figure 6. Effect of anion on thermal stability of IL with common $\left[\mathrm{C}_{4} \mathrm{mim}\right]$ cation.

\section{IL incorporation into alkaline fuel cell membranes}

In order to improve the conductivity and stability of the AFC membranes, we expect to incorporate ILs to a very stable polymer matrix. The polymers we used were polybenzimidazole (PBI) and crosslinked polyvinyl alcohol (PVA).

\section{Difficulty of incorporating ILs into PBI and crosslinked PVA membranes}

In the beginning, we used 1-butyl-3-methyl-imidazolium bis(trifluoromethylsulfonyl) imide as the IL and tried to incorporate it into the PBI or crosslinked PVA membranes. However, this IL had a very low solubility in both $\mathrm{PBI} /$ dimethyl sulfoxide (DMSO) solution and crosslinked $\mathrm{PVA} / \mathrm{H}_{2} \mathrm{O}$ solution. Phase separation occurred after solvent evaporation, which indicated that the IL was not compatible with PBI or PVA. Therefore, we used another IL (benzalkonium chloride) and $\mathrm{KOH}$ to replace the previously used IL, and we were able to prepare some homogeneous membranes. 


\section{Synthesis of PBI/ benzalkonium-OH membrane}

PBI polymer was synthesized using a one-step high temperature polymerization method from 3,3'-diaminobenzidine (DABD) and 4,4'oxybis(benzoic acid) (OBBA), using polyphosphoric acid (PPA) as the solvent ${ }^{24-26}$. Figure 7 shows the schematic of the PBI synthesis. The reaction took place under nitrogen purge at $80{ }^{\circ} \mathrm{C}$ for $2 \mathrm{~h}$ and at $200{ }^{\circ} \mathrm{C}$ for $3 \mathrm{~h}$. The yield of PBI was more than $99 \%$.

n<smiles>Nc1ccc(-c2ccc(N)c(N)c2)cc1N</smiles>

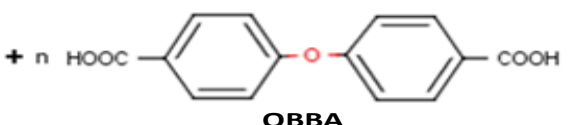

OBBA

$80^{\circ} \mathrm{C}, 2 \mathrm{~h}$;

$200^{\circ} \mathrm{C}, 3 \mathrm{~h}$

In PPA
Nitrogen Purge

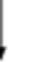<smiles>Cc1ccc(Oc2ccc(-c3nc4cc(-c5ccc6nc(C(C)(C)C)[nH]c6c5)ccc4[nH]3)cc2)cc1</smiles>

PBI

Figure 7. Schematic of the polybenzimidazole (PBI) synthesis.

The powder-like PBI polymer was dissolved in DMSO to form a homogeneous solution. To the PBI solution, certain amount of benzalkonium chloride was added. Then, the solution was poured onto a clean glass plate and cast into a membrane. The membrane was dried in an oven at $80{ }^{\circ} \mathrm{C}$ for $6 \mathrm{~h}$ and at $120{ }^{\circ} \mathrm{C}$ for $12 \mathrm{~h}$. Finally, it was soaked in $1.0 \mathrm{M} \mathrm{KOH}$ solutions for the purpose of hydroxide exchange treatment at room temperature for $24 \mathrm{~h}$. The resulting membrane in hydroxide form was washed with de-ionized water and dried at $90{ }^{\circ} \mathrm{C}$ overnight. The final membrane had a thickness of $40 \mu \mathrm{m}$.

\section{Synthesis of PBI/ KOH membrane}

PBI polymer was first dissolved in DMSO and cast into a membrane. The pure PBI membrane was soaked in $6 \mathrm{M} \mathrm{KOH}$ solution for more than $24 \mathrm{~h}$. After drying, the membrane was soaked in de-ionized water to release $\mathrm{KOH}$ into water. Then, hydrochloric acid solution was used for titration, using methyl orange as the indicator. The result showed that the PBI membrane successfully 
absorbed $\mathrm{KOH}$. The weight ratio of $\mathrm{PBI} / \mathrm{KOH}$ was about $80 / 20$. The final membrane had a thickness of around $25 \mu \mathrm{m}$.

\section{Synthesis of crosslinked PVA/ KOH membrane}

PVA was first dissolved in water under stirring at room temperature overnight and then at $80{ }^{\circ} \mathrm{C}$ for $80 \mathrm{~min}$. Then a stoichiometric amount of glutaraldehyde and a certain amount of $\mathrm{KOH}$ solution were added into the solution. The PVA/glutaric dialdehyde/ $\mathrm{KOH}$ solution was stirred at $80{ }^{\circ} \mathrm{C}$ for 2 $\mathrm{h}^{27-29}$.

Then, the solution was cast on a clean glass plate to obtain a membrane. The membrane was dried in a hood at room temperature overnight. Then, it was dried at $120{ }^{\circ} \mathrm{C}$ in a furnace for $6 \mathrm{~h}$. After drying, the final membranes was flexible and had a thickness of approximately $50 \mu \mathrm{m}$.

\section{Ex-situ electrochemical testing of the ILs}

Cyclic voltammetry was used to verify the neutrality of the ionic liquids and to ensure the ILs support $\mathrm{H}_{2}$ oxidation and $\mathrm{O}_{2}$ reduction on the electrode $\mathrm{Pt}$ surface. While we intended to test different ILs, the high viscocity at room temperature and stong adsorption on the Pt surface prevented electrochemical testing. The CVs under nitrogen atmosphere represents the electrochemical stability range of the ILs. For the IL $\left[\mathrm{C}_{4} \mathrm{mim}\right]\left[\mathrm{Tf}_{2} \mathrm{~N}\right]$ the electrochemical stable window is from approximatety $-100 \mathrm{mV}$ to $1,800 \mathrm{mV}$. The nitrogen sparged curve shows no electrochemical activity except for a redox peak at around $0.9 \mathrm{~V}$ which is also can be seen through out the experiments with other gases, as seen in Figure 8. This peak can be attributed tot the interaction of the Pt disk with the electrolyte. When the IL is sparged with $\mathrm{H}_{2}$, the hydrogen adsorption/desorption on the Pt surface can be seen at the expected potentials between $0-100 \mathrm{mV}$. In the case of oxygen sparging, we observe a negative current increase at around $850 \mathrm{mV}$. This low potential can be expected as imide base ILs show low kinetics due to the strong adsorptions of the IL on to the electrode surface. The slow reduction reaction has been observed by other reserachers in aprotic ILs ${ }^{12}$. 


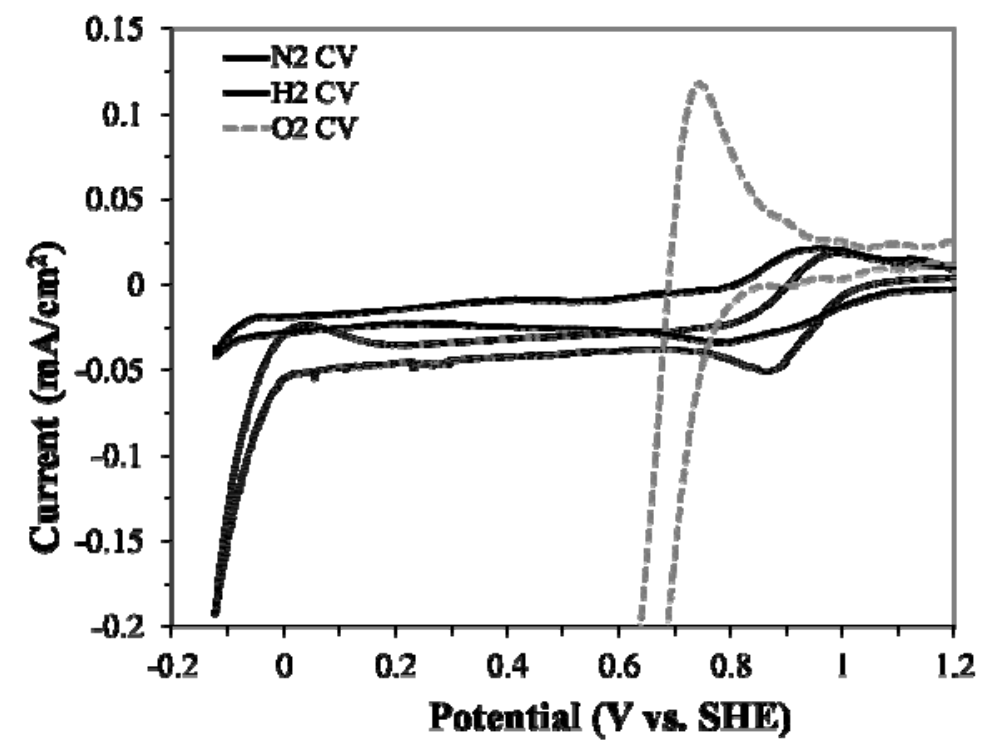

Figure 8. room temperature cyclic voltammetry of Pt disk in $\left[\mathrm{C}_{4} \mathrm{mim}\right]\left[\mathrm{Tf}_{2} \mathrm{~N}\right]$ as a function of different sparged gases at a scan rate of $5 \mathrm{mV} / \mathrm{s}$.

\section{Conductivity testing of the membrane samples}

The conductivity of the membranes was tested using a BekkTech LLC inplane conductivity cell. Sample preparation and testing protocols were acquired from the BekkTech LLC procedures document. ${ }^{30}$ In brief samples with dimensions of $5 \mathrm{~mm} \times 25 \mathrm{~mm}$ were cut and fixed into the four electrode system cell. Once in the cell, a ParStat 2273 was used to sweep the voltage from -0.1 to $0.1 \mathrm{~V}$ at a scan rate of $20 \mathrm{mV} / \mathrm{s}$. The membranes were then tested in a hydrogen atmosphere at different $\mathrm{RH}(0,30,70$ and $100 \mathrm{RH})$ and cell temperatures of 80 and $120^{\circ} \mathrm{C}$. Figure 9 depicts the effect of the different doping levels and operating condition on the ionic conductivity. As expected the conductivity increases as a function of relative humidity, however in some instances such as PVA at $120^{\circ} \mathrm{C}$, the conductivity declines. This effect can be attributed to the degradation of the membrane composite. At a given doping level we observe the overall conductivity of the PVA doped with $\mathrm{KOH}$ far superior to that of PBI doped with benzalkonium hydroxide. In the case of PVA, a relative humidity higher than 70 degraded the membrane. This result is believed to mainly be caused by a combination of loss off the doping substance and loss of mechanical stability of the membrane due to swelling as some visual degradation was 
observed. On the other hand the PBI samples showed higher degree of stability at higher relative humidities at which their ionic conductivity begins to approach that of the hydroxide based PVA membranes.

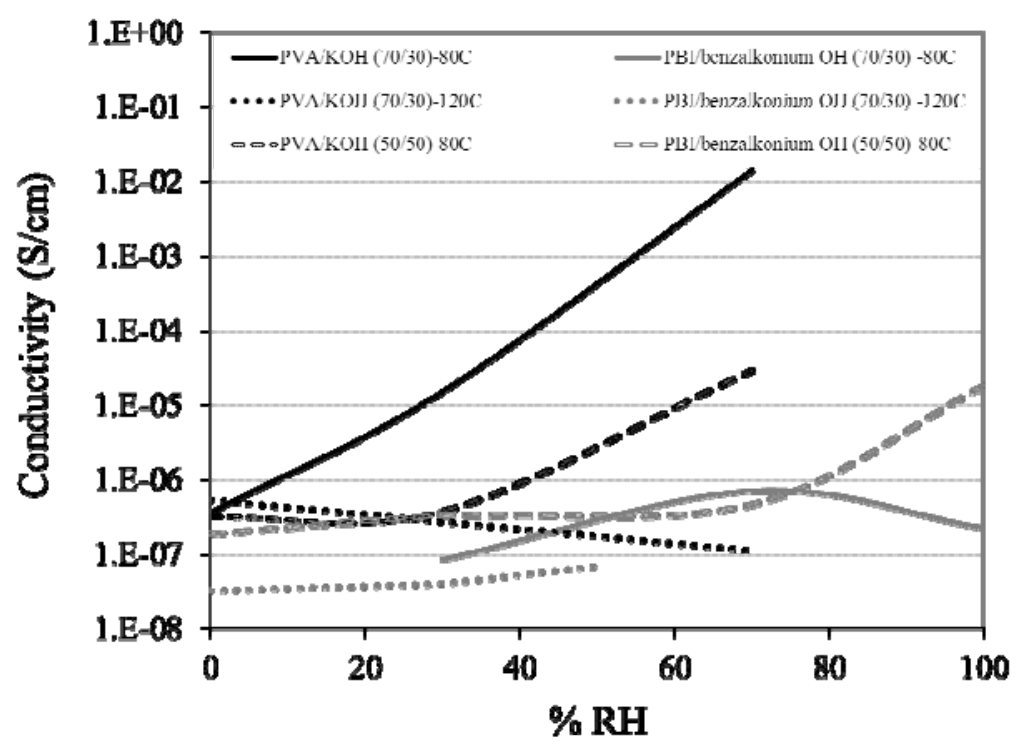

Figure 9. Membrane conductivity as a function of relative humidity and temperature.

\section{Conclusions}

Ionic liquids have been investigated for their application in PBI-based membranes in alkaline fuel cells. Although ILs show promise in terms of conductivity and thermal stability, significant work needs to be continued on the incorporation of the IL into solid polymer membranes in order to achieve validation of their operational performance in a fuel cell.

\section{Acknowledgements}

Funding for this work is greatfully acknowledged from SRNL's DOE funded Laboratory Directed Research and Development (LDRD) Program. The authors wish to thank Ann E. Visser and Nicholas J. Bridges for their discussion 
and insight on ionic liquids. Savannah River National Laboratory is operated by Savannah River Nuclear Solutions. This document was prepared in conjunction with work accomplished under Contract No. DEAC09-08SR22470 with the U.S. Department of Energy.

\section{References}

1. Kim, Y. S. In Resonance-stabilized anion exchange polymer electrolytes, DOE Annual Merit Review, Washington D.C., Washington D.C., 2010.

2. Cadena, C.; Anthony, J. L.; Shah, J. K.; Morrow, T. I.; Brennecke, J. F.; Maginn, E. J., Why is co2 so soluble in imidazolium-based ionic liquids? Journal of the American Chemical Society 2004, 126 (16), 5300-5308.

3. Bates, E. D.; Mayton, R. D.; Ntai, I.; Davis, J. H., Co2 capture by a taskspecific ionic liquid. Journal of the American Chemical Society 2002, 124 (6), 926-927.

4. Aki, S. N. V. K.; Mellein, B. R.; Saurer, E. M.; Brennecke, J. F., Highpressure phase behavior of carbon dioxide with imidazolium-based ionic liquids. The Journal of Physical Chemistry B 2004, 108 (52), 20355-20365.

5. Wilkes, J. S.; Levisky, J. A.; Wilson, R. A.; Hussey, C. L., Dialkylimidazolium chloroaluminate melts: A new class of room-temperature ionic liquids for electrochemistry, spectroscopy and synthesis. Inorganic Chemistry 1982, 21 (3), 1263-1264.

6. Hou, H.; Sun, G.; He, R.; Wu, Z.; Sun, B., Alkali doped polybenzimidazole membrane for high performance alkaline direct ethanol fuel cell. J. Power Sources 2008, 182, 95-99.

7. Varcoe, J. R.; Slade, R. C. T., Fuel Cells 2005, 5, 187-200.

8. Wang, A.; Li, A.; Zhang, S., Macromolecules 2010, 43, 3890-3896.

9. Xing, B.; Savadogo, O., Hydrogen/oxygen polymer electrolyte membrane fuel cells (pemfcs) based on alkaline-doped polybenzimidazol (pbi). Electrochemistry Communications 2000, 2, 697-702.

10. McLean, G. F.; Niet, T.; Prince-Richard, S.; Djilali, N., Int. J. Hydro. Energy 2002, 27, 507-526.

11. Lee, S.-Y.; Yasuda, T.; Watanabe, M., J. Power Sources 2010, 195, 59095914.

12. Nakamoto, H.; Watanabe, M., Chem. Commun. 2007, (2539-2541).

13. Belieres, J.-P.; Gervasio, D.; Angell, C. A., Chem. Commun. 2006, 47994801.

14. Rollins, J. B.; Conboy, J. C., J. Electrochem. Soc. 2009, 156, B943-B954.

15. Yan, F.; Yu, S.; Zhang, X.; Qiu, L.; You, J.; Lu, J., Chem. Mater. 2009, (1480-1487). 
16. Peng, Y.; Li, G.; Li, J.; Yu, S., Convenient syntheisi of various ionic liquids from onium hydroxides and ammonium salts. Tetrahedron Letters 2009, 50, 4286-4288.

17. Ranu, B. C.; Banerjee, S., Ionic liquid as catalyst and reaction medium. The dramatic influence of task-specific ionic liquid, [bmim][oh], in michael addition of active methylene compounds to conjugated ketones, carboxylic esters, and nitriles. Organic Letters 2005, 7 (14), 3049-3052.

18. Yoshizawa, M.; Ohno, H., Fuel cell. In Electrochemical aspects of ionic liquids, Ohno, H., Ed. John Wiley \& Sons, Inc.: New York, NY, 2005; pp 199203.

19. Danten, Y.; Cabaço, M. I.; Besnard, M., Interaction of water highly diluted in 1-alkyl-3-methyl imidazolium ionic liquids with the pf6- and bf4- anions. The Journal of Physical Chemistry A 2009, 113 (12), 2873-2889.

20. Rivera-Rubero, S.; Baldelli, S., Influence of water on the surface of hydrophilic and hydrophobic room-temperature ionic liquids. Journal of the American Chemical Society 2004, 126 (38), 11788-11789.

21. Li, Q.; He, R.; Jensen, J. O.; Bjerrum, N. J., Approaches and recent development of polymer electrolyte membranes for fuel cells operating above $100{ }^{\circ} \mathrm{c}$. Chemistry of Materials 2003, 15 (26), 4896-4915.

22. Lee, S.-Y.; Ogawa, A.; Kanno, M.; Nakamoto, H.; Yasuda, T.; Watanabe, M., Nonhumidified intermediate temperature fuel cells using protic ionic liquids. Journal of the American Chemical Society 2010, 132 (28), 9764-9773.

23. Fox, E. B.; Smith, L. T.; Williamson, T. K.; Bridges, N. J.; Visser, A. E., Long-term aging effects on c-4 imide based ionic liquids. Green Chem. 2012, in progress.

24. Bai, H.; Ho, W. S. W., New sulfonated polybenzimidazole (spbi) copolymer-based proton-exchange membranes for fuel cells. J. Taiwan Inst. Chem. Engrs. 2009, 43 (3), 260-267.

25. Bai, H.; Ho, W. S. W., New carbon dioxide-selective membranes based on sulfonated polybenzimidazole (spbi) copolymer matrix for fuel cell applications. Ind. Eng. Chem. Res. 2009, 48 (5), 2344-2354.

26. Bai, H.; Ho, W. S. W., Polym. Int. 2011, 60, 26-41.

27. Zou, J.; Ho, W. S. W., J. Membr. Sci. 2006, 286, 310-321.

28. Bai, H.; Ho, W. S. W., Ind. Eng. Chem. Res. 2011, 50, 12152-12161.

29. Xing, R.; Ho, W. S. W., J. Membr. Sci. 2011, 367, 91-102.

30. . Bekktech's procedures for performing in-plane membrane conductivity testing (2008). U.S. Department of Energy. http://www.bekktech.com/dwnlds/ConductivityTesting.pdf. 